OPEN ACCESS

Edited by:

Haluk Ogmen,

University of Houston, USA

Reviewed by:

Olivia Carter,

University of Melbourne, Australia

Jan Brascamp,

Michigan State University, USA

*Correspondence:

Dingcai Cao

dcao98@uic.edu;

Sang W. Hong

shong6@fau.edu

tPresent address:

Xiaohua Zhuang,

Institute for Mind and Biology, The University of Chicago, Chicago,

IL 60637, USA

Para Kang,

$D M C$ R\&D Center, Samsung

Electronics Co. Ltd.,

Gu Suwon-Shi, Korea

Specialty section:

This article was submitted to

Perception Science,

a section of the journal

Frontiers in Psychology

Received: 30 October 2015

Accepted: 21 March 2016

Published: 06 April 2016

Citation:

Cao D, Zhuang X, Kang P, Hong SW and King AC (2016) Acute Alcohol

Drinking Promotes Piecemeal

Percepts during Binocular Rivalry.

Front. Psychol. 7:489.

doi: 10.3389/fpsyg.2016.00489

\section{Acute Alcohol Drinking Promotes Piecemeal Percepts during Binocular Rivalry}

\author{
Dingcai Cao ${ }^{1 *}$, Xiaohua Zhuang ${ }^{1 \dagger}$, Para Kang ${ }^{11}$, Sang W. Hong ${ }^{2 *}$ and Andrea C. King ${ }^{3}$ \\ ${ }^{1}$ Department of Ophthalmology and Visual Sciences, University of Illinois at Chicago, Chicago, IL, USA, ${ }^{2}$ Department of \\ Psychology and Center for Complex Systems and Brain Sciences, Florida Atlantic University, Boca Raton, FL, USA, \\ ${ }^{3}$ Department of Psychiatry and Behavioral Neuroscience, The University of Chicago, Chicago, IL, USA
}

Binocular rivalry refers to perceptual alternation when two eyes view different images. One of the potential percepts during binocular rivalry is a spatial mosaic of left- and righteye images, known as piecemeal percepts, which may result from localized rivalries between small regions in the left- and right-eye images. It is known that alcohol increases inhibitory neurotransmission, which may reduce the number of alternations during binocular rivalry. However, it is unclear whether alcohol affects rivalry dynamics in the same manner for both coherent percepts (i.e., percepts of complete left or right images) and piecemeal percepts. To address this question, the present study measured the dynamics of binocular rivalry before and after 15 moderate-to-heavy social drinkers consumed an intoxicating dose of alcohol versus a placebo beverage. Both simple rivalrous stimuli consisting of gratings with different orientations, and complex stimuli consisting of a face or a house were tested to examine alcohol effects on rivalry as a function of stimulus complexity. Results showed that for both simple and complex stimuli, alcohol affects coherent and piecemeal percepts differently. More specifically, alcohol reduced the number of coherent percepts but not the mean dominance duration of coherent percepts. In contrast, for piecemeal percepts, alcohol increased the mean dominance duration but not the number of piecemeal percepts. These results suggested that alcohol drinking may selectively affect the dynamics of transitional period of binocular rivalry by increasing the duration of piecemeal percepts, leading to a reduction in the number of coherent percepts. The differential effect of alcohol on the dynamics of coherent and piecemeal percepts cannot be accounted for by alcohol's effect on a common inhibitory mechanism. Other mechanisms, such as increasing neural noise, are needed to explain alcohol's effect on the dynamics of binocular rivalry.

Keywords: binocular rivalry, piecemeal percept, acute alcohol effect

\section{INTRODUCTION}

Binocular rivalry refers to perceptual alternations between two different images presented simultaneously to the two eyes (Blake and Logothetis, 2002). Neural mechanisms mediating binocular rivalry have been the center of debate for many decades. The general consensus is that binocular rivalry is mediated by neural competition that occurs at multiple stages in the 
visual hierarchy (Blake and Logothetis, 2002; Wilson, 2003; Tong et al., 2006; Alais, 2012). One of the neural models for binocular rivalry posits that reciprocal inhibition between visual neurons representing left- and right-eye images and self-adaptation in neural signals determine the dynamics of rivalry (Lehky, 1988; Blake, 1989; Wilson, 2003, 2007). Consistent with this model, it has been demonstrated that a higher brain concentration of the inhibitory neurotransmitter gamma-aminobutyric acid (GABA) was associated with a low alternation rate in bi-stable percepts, including binocular rivalry (van Loon et al., 2013). In addition, it has been shown that visual adaptation (Blake et al., 2003; Alais et al., 2010; Kang and Blake, 2010; Theodoni et al., 2011) and attention (Mitchell et al., 2004; Chong et al., 2005; Chong and Blake, 2006; Paffen et al., 2006; Hancock and Andrews, 2007; Zhang et al., 2011) are critical determinants of binocular rivalry dynamics.

When two dissimilar images presented to the two eyes are relatively large, in addition to the coherent percepts of the left- or right-eye images, one can also experience piecemeal percepts, in which patches of left- and right-eye images are visible simultaneously (Kovács et al., 1996; Polonsky et al., 2000; Lee and Blake, 2004). Previous studies show that piecemeal percept rarely occurs if the dissimilar images are smaller than about $7 \mathrm{~min}$ of arc in visual angle at fovea (Blake et al., 1992), indicating that binocular rivalry occurs at local regions and the perceptual outcome during rivalry depends on local competitions. In other words, the coherent perception of a left- or right-eye image likely requires joint predominance of local rivalries (Fries et al., 1997; Alais and Blake, 1999).

Are piecemeal percepts during binocular rivalry also mediated by the same inhibitory/adaptation mechanism as coherent percepts? Despite the extensive efforts devoted to understand the mechanisms mediating perceptual switches between coherent rivalrous images during binocular rivalry, the mechanism for piecemeal percepts is less clear. It has been shown that the principles of Gestalt perceptual grouping, such as feature similarity and good continuation, can affect the joint predominance of local rivalries (Kovács et al., 1996; Alais and Blake, 1999; Stuit et al., 2011). Besides this grouping-based account, computational models have been developed to account for piecemeal percepts. For instance, Stollenwerk and Bode (2003) assumes that multiple neurons represent different spatial zones in the images and those representations of corresponding zones in the two-eye images compete with each other through inhibition and adaptation. When the dominant patterns differ among different zones, piecemeal percepts occur. In addition, piecemeal percepts are considered as a result from the transitional period between the two coherent percepts for the left- and righteye images and neural noise has been suggested to play a critical role in resolving rivalry during the transition period between two rivalrous percepts (Brascamp et al., 2006; Kang and Blake, 2010).

Acute alcohol drinking is known to increase inhibition in the central nervous system by increasing inhibitory neurotransmission or by inhibiting excitatory neurotransmission (Valenzuela, 1997; Grobin et al., 1998). Therefore, acute alcohol administration can be thought as a pharmacological manipulation of the inhibitory system that can affect binocular rivalry dynamics. Studies have shown that acute alcohol consumption reduces the alternation rate between left- and right-eye percepts during binocular rivalry, consistent with alcohol's increase in neural inhibitory effects (Barany and Hallden, 1947; Donnelly and Miller, 1995). These studies, however, have focused on coherent percepts only and have not considered the influence of alcohol consumption on piecemeal percepts. This is important as the knowledge of alcohol's effect on the dynamics of piecemeal percepts may provide insights in the mechanisms for the dynamics of binocular rivalry. We hypothesized that if a common (inhibition) mechanism determines perceptual experiences of both coherent and piecemeal percepts during binocular rivalry, alcohol would affect the rivalry dynamics in the same manner for both coherent and piecemeal percepts.

\section{MATERIALS AND METHODS}

\section{Participants}

We focused on testing young moderate and heavy social drinkers, because this population can tolerate the alcohol dose used in the study without significant adverse effects and they are at risk for alcohol-related harm but have not incurred significant withdrawal or other clinical symptoms that might confound our measurements (Caetano et al., 1998). Young moderate-toheavy social drinkers were recruited via internet advertisements and were screened using online screening questionnaires and interview, which included demographic information, medical information (eye disease, heart disease, diabetes, high blood pressure, mental health, etc.), the Alcohol Quantity-Frequency Interview (Cahalan et al., 1969) and the Timeline Follow-back calendar (Sobell et al., 1979) for daily estimates of alcohol drinking. Inclusion criteria were: having normal or correctedto-normal acuity, not reporting any health and psychiatric problems including alcohol dependence that might interfere with the study procedures, consuming at least 6 or more alcoholic drinks weekly (up to 35) and engaging in binge drinking [consuming $5+$ drinks/occasion for men and $4+$ for women (Substance Abuse and Mental Health Services Administration [SAMHSA], 2005] at least twice monthly up to four times weekly.

There were 15 participants [six males and nine females, age 25 (mean $) \pm 2.4(S D)$ years; number of drinking days per month: $11.5 \pm 5.2$; number of standard drinks per drinking day: $1.3 \pm 0.4$; number of binge days per month: $4.4 \pm 2.2$; maximum number of drinks consumed on one occasion: $7.7 \pm 2.9$ ]. This study was approved by the University of Illinois at Chicago Institutional Review Board and was in compliance with the Declaration of Helsinki.

\section{Overall Design and Protocol}

The experiment used a within-subject, double-blinded and placebo-controlled design. Each participant received either an intoxicating dose of alcohol $(0.8 \mathrm{~g} / \mathrm{kg}$, i.e., equivalent to $4-5$ standard alcohol drinks (King et al., 2011; Zhuang et al., 2012) 
or placebo beverage on two separate days. The alcoholic beverage consisted of $16 \%$ volume ethanol, which contained 190-proof ethanol mixed with water, grape-flavored drink mix and a sucralose-based sugar substitute. The placebo beverage included $1 \%$ volume ethanol as a taste mask to reduce expectancy effects. Participants drank the assigned beverage through a straw from a plastic, lidded cup to help conceal the scent and identification of the alcohol content. Women received $85 \%$ of the dose of men as a correction for body water differences (Watson et al., 1980). The total beverage volume was (mean) $435.3 \pm(S D) 81.6 \mathrm{ml}$ and divided into two equal portions.

The order of the two beverage administrations was randomized, with a minimum of a 48-hour interval between the sessions. The participants were instructed to abstain from alcohol and recreational drugs for 48 hours prior to each session, and both participant and experimenter were double-blinded to the beverage content. To verify alcohol abstinence, breath alcohol concentration (BrAC) was measured using an Alco-Sensor IV (Intoximeter Inc., St. Louis, MO, USA) upon arrival in each experimental session. Following BrAC measurement, the participant was provided with a light snack (non-caffeine, low-fat meal at $15 \%$ calories based on body weight) and then taken to a dark room for the binocular rivalry experiment. The participants received a tutorial and practice period in the first session, followed by the pre-beverage assessment. After this assessment, the participants drank the assigned beverage. They had 5 min to consume the first half portion, followed by a 5 -min rest period, and then another $5 \mathrm{~min}$ to finish the second half portion. Postbeverage measurements of binocular rivalry were conducted 50 minutes after completing beverage intake. BrAC levels were measured before the binocular rivalry experiment during preand post-beverage assessments. This beverage administration procedure has been used extensively in previous studies and has shown reliable rising and declining breath alcohol concentration (BrAC) curves across participants (Brumback et al., 2007; King et al., 2011; Zhuang et al., 2015). The BrAC levels were all zero at baseline for both sessions, confirming recent alcohol abstinence in all participants. Post-beverage BrAC levels, measured right before the binocular rivalry testing, were at $0.071 \pm 0.011 \mathrm{~g} / \mathrm{dl}$ in the alcohol session or at zero in the placebo session.

\section{Apparatus}

Stimuli were generated using an Apple iMac computer and presented on a calibrated NEC cathode ray tube (CRT) display (MultiSync FE 991 SB). The display had $1600 \times 1200$ pixel resolution and a refresh rate of $60 \mathrm{~Hz}$ noninterlaced. Different stimuli were presented to each eye by projection through a mirror haploscope. The positions of the mirrors were adjusted for each participant in order to compensate for the differences in interpupillary distance.

\section{Visual Stimuli}

As prior studies have examined alcohol's effects on only simple geometric stimuli such as sine-wave gratings, it is unclear whether alcohol affects binocular rivalry with complex recognizable stimuli (e.g., between a house and a face). Such complex recognizable stimuli are perceived longer during binocular rivalry
(Hastorf and Myro, 1959; Yu and Blake, 1992), indicating discrepancy in rivalry dynamics between simple geometric stimuli and complex recognizable stimuli. Thus we used two sets of stimuli in the main experiment (Figure 1), including: (1) simple stimuli that consisted of two orthogonal sinusoidal gratings $\left(45^{\circ}\right.$ vs. $135^{\circ}$, Figure 1A) at the same spatial frequency of 4 cycle/degree, and (2) complex stimuli that consisted of a house and a face (Figure 1B). The size of all stimuli was $1^{\circ} \times 1.5^{\circ}$. Several thin rectangular lines guided fixation. The mean luminance of all stimuli was $23.5 \mathrm{~cd} / \mathrm{m}^{2}$. The root mean square (RMS) contrasts of all stimuli were kept constant and minimum and maximum luminance were 5 and $42 \mathrm{~cd} / \mathrm{m}^{2}$, respectively, leading to a Michelson contrast of $79 \%$.

\section{Binocular Rivalry Measurement Procedure}

Each experiment began with the presentation of the rectangular thin, fusion guidelines. The participants adjusted the mirrors in order to get good alignment of left- and right-eye images. When ready, the participants pressed a button in a Gamepad to start a trial, during which both the left- and right-eye stimuli were presented continuously for 40 seconds. The participants reported their perceptual experience (either one of the coherent percepts or piecemeal percept) by continuously holding a button until the percept changed. Separate buttons were assigned to report three different percepts in the experiment: percept of the left-eye stimulus, percept of the right-eye stimulus, and piecemeal percept (Figure 1, right column). The duration of each percept was measured by taking the duration of holding a designated button. Once a trial was completed, the participants could rest and pressed a button to start the next trial. Each experiment consisted of eight trials (two stimulus types $\times$ four repeats), which were presented in a random order. For each stimulus type, the presentation was counterbalanced across the left and right eyes. For example, for the simple stimuli, the $45^{\circ}$ grating were presented to the left eye in two trials and to the right eye in the other two trials. Each experiment lasted for approximately $15 \mathrm{~min}$. Each participant completed four binocular rivalry measurements (pre-placebo, post-placebo, prealcohol, and post-alcohol).

\section{Statistical Analysis}

To simplify the analysis, the reported percepts were grouped into two categories, coherent percepts (i.e., perceiving the leftor right-eye image) and piecemeal percepts. For each trial, we calculated the time to rivalry onset (Casanova et al., 2013), the first percept category and duration, the total number of percepts (coherent and piecemeal percepts combined), and perceptspecific total dominance duration (i.e., total time perceiving a specific percept in a trial), the number of percepts and mean dominance duration. The mean dominance duration was computed as dividing the total dominance duration by the number percepts for each category of percepts (coherent and piecemeal). Trials with time to rivalry onset $\geq 5 \mathrm{~s}$ (account for $2.3 \%$ of the total number of trials) were removed. For each test condition (Stimulus Type $\times$ Beverage Type $\times$ Time 
combination), percepts with the largest $2 \%$ and lowest $2 \%$ of mean dominance durations were excluded from analyses to avoid percepts with extremely short or long duration.

The time to rivalry onset, first percept category and duration, the number of percepts and dominance duration were analyzed using Generalized Estimation Equation (GEE) (Zeger and Liang, 1986) models that could account for within-subject correlations among repeated measurements and have a flexibility in fitting data with various distributions. We used a Gaussian distribution for modeling the log-transformed time to rivalry onset and logtransformed total dominance duration, a Binomial distribution for the first percept category and a Poisson distribution for modeling the number of percepts. It has been suggested that the reciprocal of dominance duration instead of the mean dominance durations follows a Gamma distribution (Brascamp et al., 2005) and we confirmed this is the case (see Figure 2 for the pre-beverage rivalry data with the simple stimuli during the placebo session). Therefore, we calculated the reciprocal transformation for mean dominance duration and used a gamma distribution in the GEE modeling. For the time to rivalry onset, first percept category, and the total number of percepts, the GEE model included Stimulus Type (simple vs. complex stimuli), Beverage Type (placebo vs. alcohol), Measurement Time (pre- vs. post-beverage), and their interactions. For perceptspecific measures (first percept duration, total dominance duration, number of percepts and mean dominance duration),

\section{A}

\section{Simple Stimuli}

Stimuli

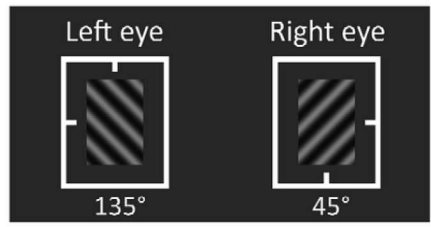

B

Complex Stimuli

Stimuli

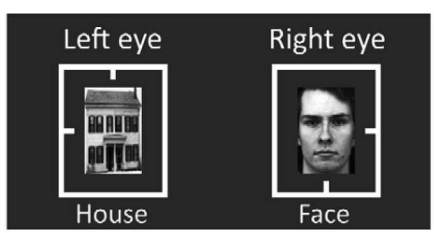

Reported Percepts

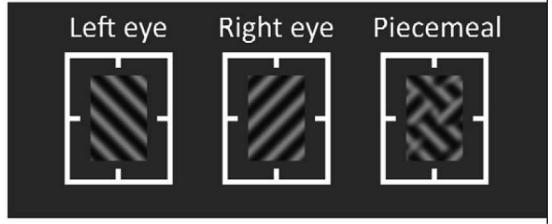

Reported Percepts

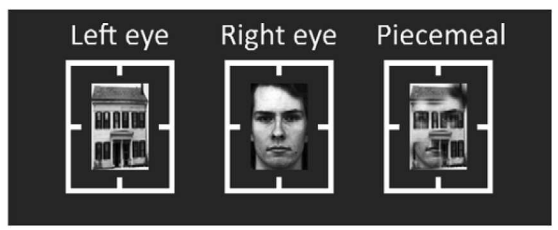

FIGURE 1 | Binocular rivalry stimuli and reported percepts in Experiments 1 and 2. (A) Simple stimuli, gratings with two different orientations, and (B) Complex stimuli, house and face images. Reported percepts comprised of left-eye image, right-eye image, and piecemeal of left- and right-eye images.
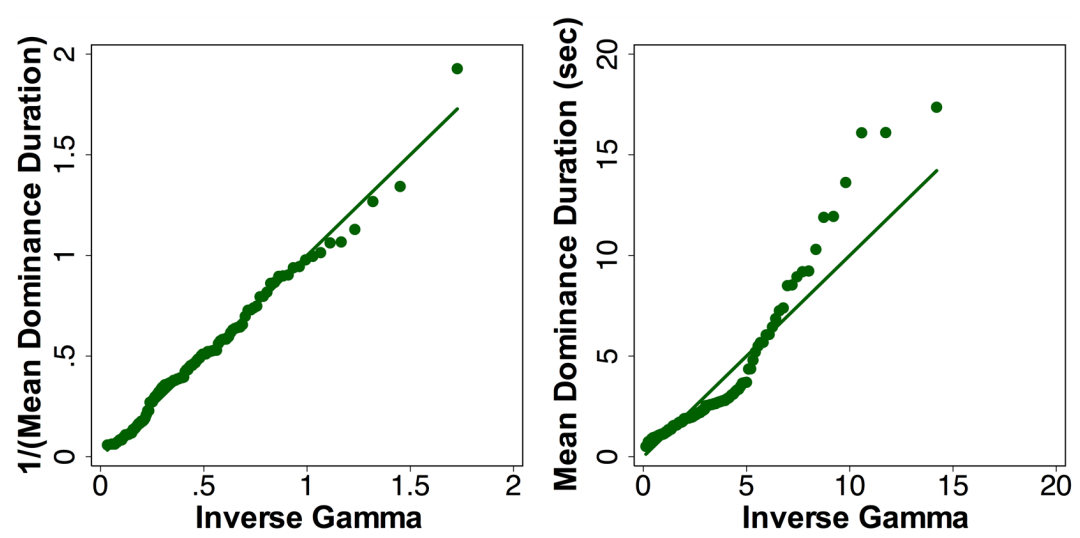

FIGURE 2 | The quantiles of the reciprocal of mean dominance duration (left) or mean dominance duration (right) versus the quantiles of a fitted gamma distribution for pre-beverage measurement during the placebo session with the simple grating stimuli. A gamma distribution described the reciprocal of mean dominance duration better than the dominance duration. 
A

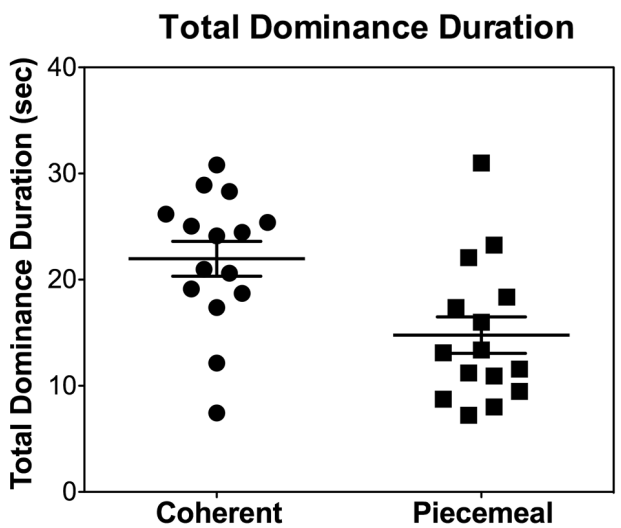

B

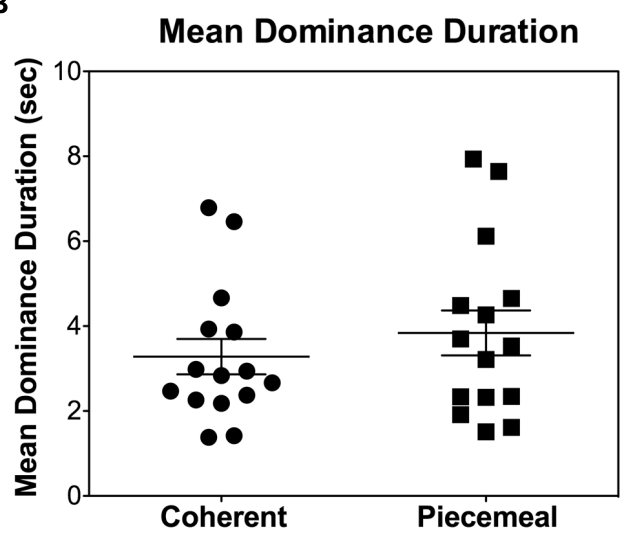

FIGURE 3 | Individual differences in (A) total dominance duration per trial (40 s) and (B) mean dominance duration for each of the participants during the placebo session, collapsing the stimulus types and measurement times. Each symbol represents one individual.

the GEE models included Stimulus Type (simple vs. complex stimuli), Percept Category (coherent vs. piecemeal), Beverage Type (placebo vs. alcohol), Measurement Time (pre- vs. postbeverage), and their interactions. Following each of the GEE models, we used linear contrast tests to test the model terms (main effects or interactions). We were primarily interested in the significance of several interaction terms in the models, including (1) Beverage Type $\times$ Time to test the alcohol effect, (2) Percept Category $\times$ Beverage Type $\mathrm{x}$ Time to test whether the alcohol effect depended on the perception category, and (3) Stimulus Type $\mathrm{x}$ Beverage $\mathrm{x}$ Time or Stimulus Type $\times$ Percept Category $\times$ Beverage $\times$ Time to test whether the alcohol effect depended on the stimulus types. In the case that one of the above mentioned interaction terms was significant, we then conducted post-estimation pairwise comparisons to compare pre-beverage and post-beverage values within a session for each stimulus type at the Bonferroni corrected significance level of 0.0125 (i.e., four post-estimation comparisons for each stimulus type).

\section{RESULTS}

There were large individual differences in terms of total dominance duration or mean dominance duration for coherent and piecemeal percepts (see Figure 3 rivalry data during the placebo session, collapsing stimulus types and measurement time), with some subjects predominantly perceiving coherent percepts while others had a more balanced coherent and piecemeal predominance. Note that the participants in our study were moderate-to-heavy alcohol drinkers (in contrast, typical binocular rivalry studies used normal subjects probably with a light drinking pattern). It is known that chronic alcohol exposure may change the balance of inhibitory and excitatory processes in the brain (Valenzuela, 1997), potentially leading to a large individual difference. However, our sample size was not large enough to assess the association between drinking history and predominance pattern so this issue was outside of the scope of this paper.
Alcohol significantly reduced the total dominance duration for coherent percepts and increased the total dominance duration for piecemeal percepts [Percept Category $\times$ Beverage Type $\mathrm{x}$ Time: $\chi^{2}(1)=21.95, p<0.001$; Figure 4] and this alcohol effect was not related to stimulus types [Stimulus Type $\times$ Percept Category $\times$ Beverage Type $\times$ Time: $\left.\chi^{2}(1)=0.14, p=0.707\right]$. Subsequent pairwise comparisons for both stimulus types showed that alcohol increased post-beverage total piecemeal duration (or a decreased post-beverage total coherent duration) compared with the pre-beverage measurement but this was not the case in the placebo session (Figure 4).

As the total dominance duration is determined by the number of percepts and the mean dominance duration of each percept category, we analyzed alcohol's effect on the number of percepts and mean dominance duration separately. For both stimulus types (simple and complex), alcohol decreased the number of percepts for coherent percepts but not for piecemeal percepts [Percept Category $\times$ Beverage Type $\times$ Time: $\chi^{2}(1)=16.20$, $p<0.001$; Stimulus Type $\times$ Percept Category $\times$ Beverage Type $\times$ Time : $\chi^{2}(1)=0.93, p=0.334$; Figure 5A] On the other hand, for both simple and complex stimuli, alcohol significantly increased the mean dominance duration for piecemeal percepts but not for coherent percepts [Percept Category $\mathrm{x}$ Beverage Type $\mathrm{x}$ Time: $\chi^{2}(1)=6.63, p=0.01$; Stimulus Type $\mathrm{x}$ Percept Category $\mathrm{x}$ Beverage Type $\mathrm{x}$ Time : $\chi^{2}(1)=0.18, p=0.671$; Figure 5B]. Finally, alcohol did not affect time to rivalry onset (Figure 6A), the first percept category (Figure 6B), or first percept duration (Figures 6C,D) significantly for both stimulus types. These results indicate that alcohol affects coherent and piecemeal percepts differently. That is, alcohol reduced the number of coherent percepts (without changing mean dominance duration) but increased mean dominance duration for piecemeal percepts (without changing the number of piecemeal percepts), leading to a reduction in total coherent percept duration but an increase in total piecemeal duration (Figure 4).

It is known that acute alcohol intake impairs contrast sensitivity (Pearson and Timney, 1998; Zhuang et al., 2012). 
Therefore, the alcohol's effects on the dynamic of binocular rivalry may be in fact due to the impaired contrast sensitivity and decreased stimulus visibility from alcohol. To test this possibility, we measured binocular rivalry dynamics using the same stimuli while varying the contrasts $(79,59$, or $39 \%$, mean luminance at $23.5 \mathrm{~cd} / \mathrm{m}^{2}$ ) in 4 lab personnel (one male and three females, age $26.8 \pm 7.2$ years, light drinkers) without alcohol intake. This control experiment showed that for both stimuli types, reducing contrast increased the mean dominance duration for coherent percepts but not for piecemeal percepts (Figure 7), indicating that a decrease in stimulus visibility could not explain the alcohol effects on piecemeal percepts (Figure 5B).
A

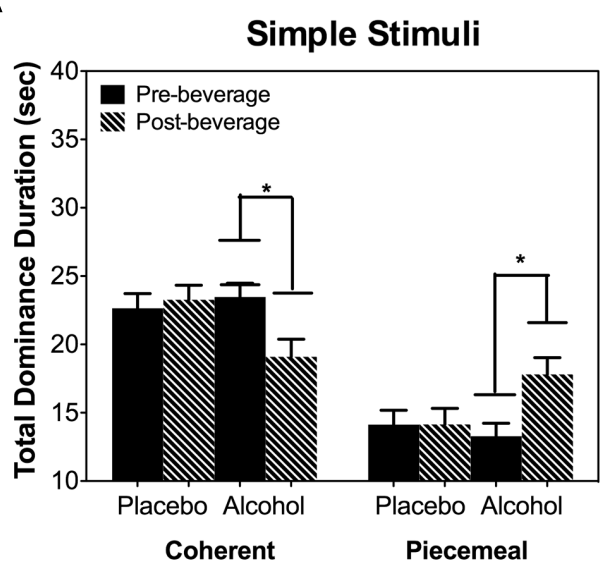

B

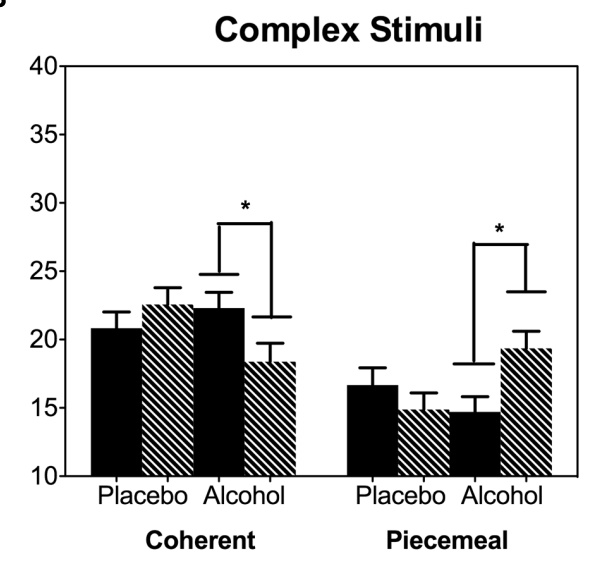

FIGURE 4 | Total dominance duration per trial (40 s) of coherent or piecemeal percepts for the simple stimuli (A) and complex stimuli (B). Error bars are \pm SEM. ${ }^{*} p<0.0125$ for paired comparisons between pre- and post-beverage measurements in the same session.

A
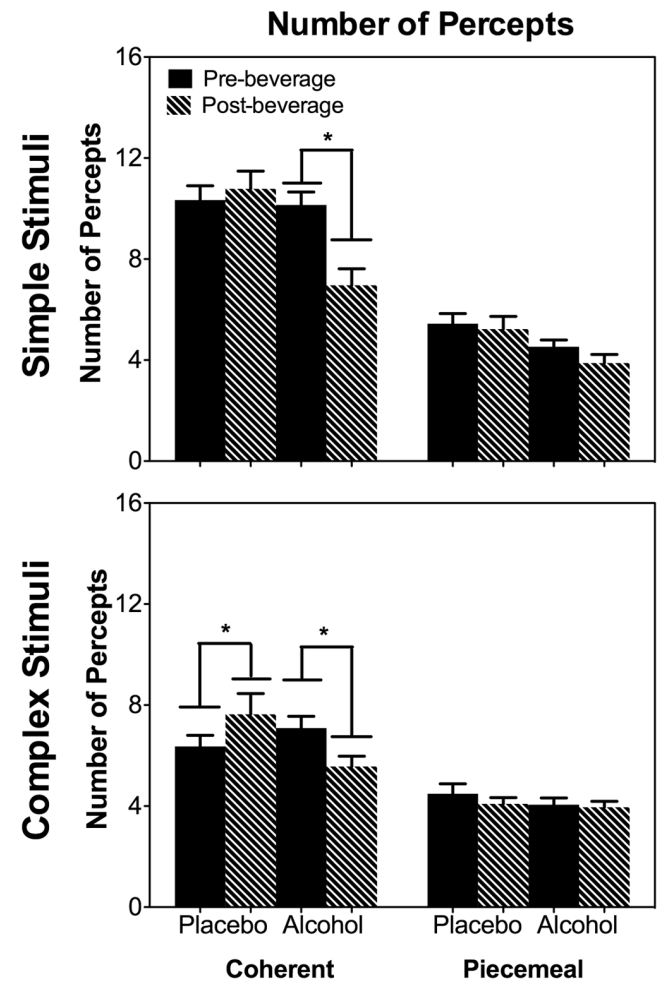

B
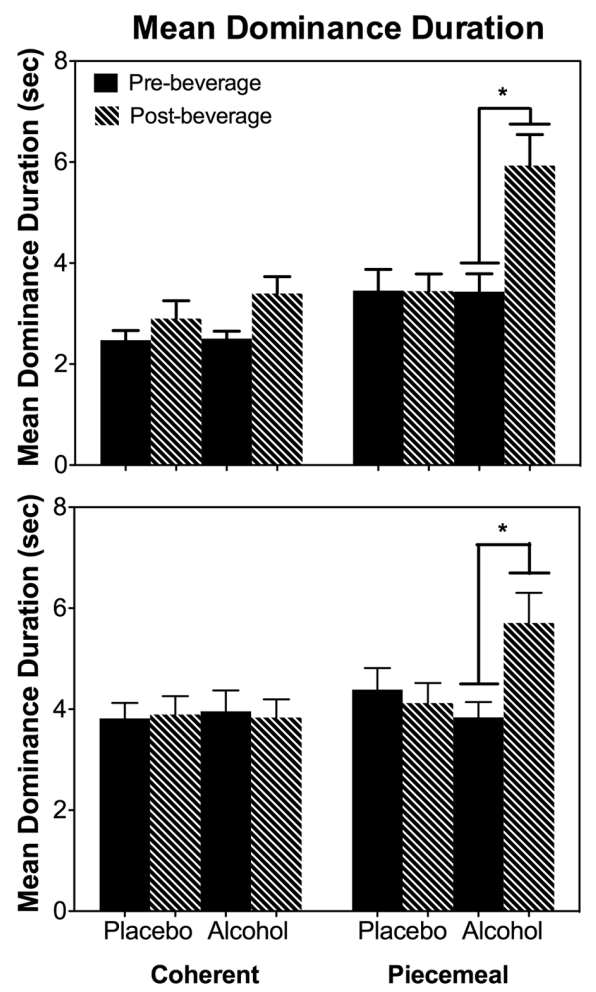

FIGURE 5 | The number of percepts (A) and mean dominance duration (B) measured at Pre- and Post-beverage for Placebo and Alcohol sessions for the two stimulus types, simple stimuli (top), and complex stimuli (bottom). Error bars are \pm SEM. * $p<0.0125$ for paired comparisons between pre- and post-beverage measurements in the same session. 
A

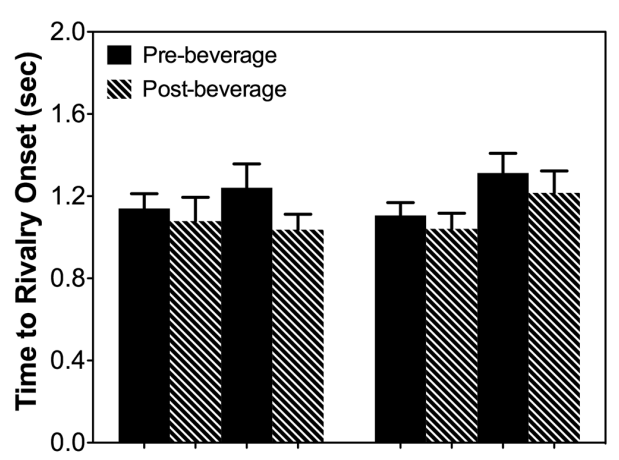

B

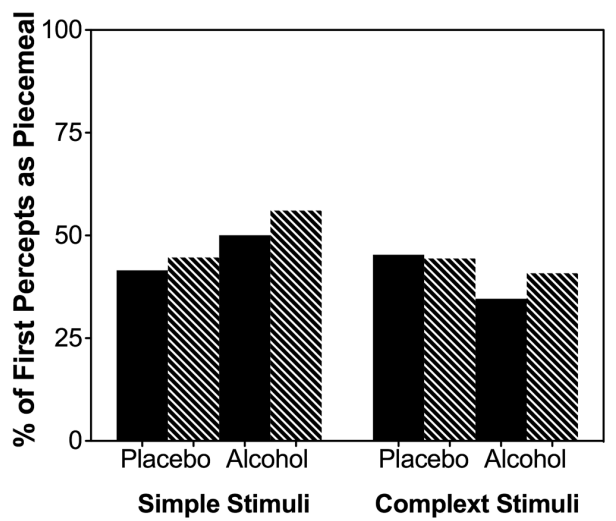

C

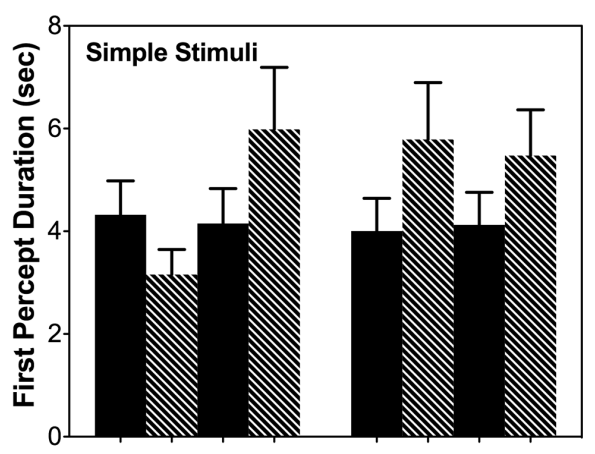

D

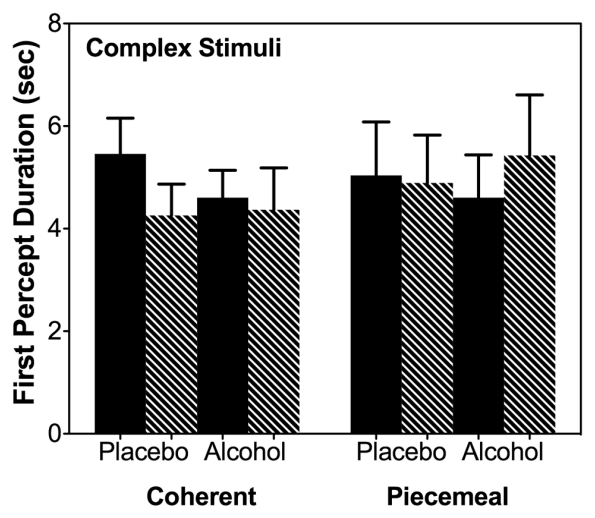

FIGURE 6 | Time to rivalry onset (A), first percept category (B) and first percept duration for the simple stimuli (C) and complex stimuli (D). Error bars are \pm SEM.

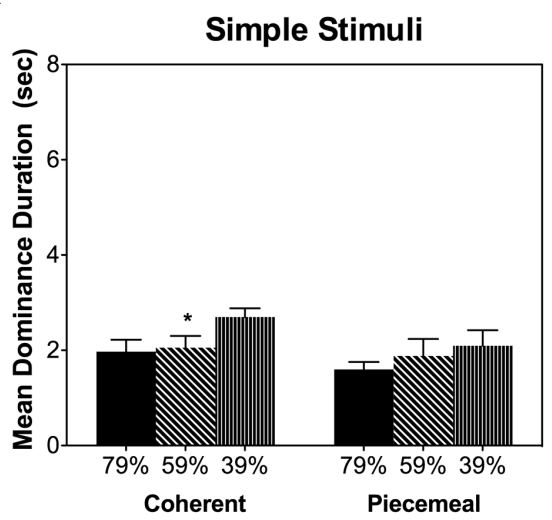

B

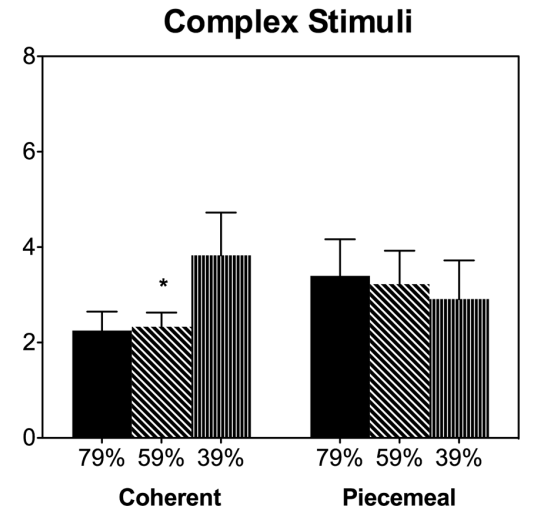

FIGURE 7 | Mean dominance duration for different percept categories in the control experiment for the simple stimuli (A) and complex stimuli (B). Error bars are \pm SEM. ${ }^{*} p<0.0125$ for post-estimation paired comparisons.

\section{DISCUSSION}

Acute alcohol intake impairs various aspects of visual processing (Khan and Timney, 2007; Kunchulia et al., 2012; Zhuang et al., 2012, 2015). Here, we investigated whether acute alcohol intake altered the dynamics of binocular rivalry, including coherent and piecemeal percepts. We hypothesized that if a common mechanism determines perceptual experiences of both coherent and piecemeal percepts during binocular rivalry, alcohol would affect the rivalry dynamics in the same manner for both coherent and piecemeal percepts. Consistent with previous studies (Barany and Hallden, 1947; Donnelly and Miller, 1995), the current study also showed that acute alcohol intake slowed down the number of percepts between seeing coherent percepts during binocular rivalry (Figure 5A). However, alcohol affected the dynamics of piecemeal percepts differently from coherent percepts. For 
coherent percepts, alcohol reduced the number of percepts but not the mean dominance duration, and for piecemeal percepts, it was the opposite (alcohol did not reduce the number of percepts but did increase the mean dominance duration). Therefore, our hypothesis was not supported.

Based on Levelt's Fourth proposition, increasing stimulus strength (e.g., stimulus contrast) in both eyes while keeping stimulus strength equal between eyes will generally increase the alternation rate or reduce dominance duration (Levelt, 1965; Brascamp et al., 2015). Acute alcohol intake is known to impair contrast sensitivity, leading to a weaker stimulus strength (visibility) (Pearson and Timney, 1998; Zhuang et al., 2012). Therefore, alcohol could affect the dynamic of binocular rivalry through it's reduction in contrast sensitivity. Our control experiment, however, showed that changing luminance contrast affects mean dominance duration of coherent percepts but not piecemeal percepts, suggesting that it is unlikely that alcohol's increase in piecemeal percept duration was due to alcohol's reduction in contrast sensitivity. Mueller and Blake (1989) showed the predominance time of piecemeal percepts did not vary with stimulus contrast in binocular rivalry, similar to our results from the control experiment. Interestingly, using a binocular motion rivalry paradigm (Platonov and Goossens, 2013), an increase in random dot coherence led to an increase in dominance duration of piecemeal percepts, a result similar to our observed alcohol's effect, while changing stimulus contrast did not change piecemeal percept duration. Given the random-dot-coherence and contrast manipulations had different effects on rivalry dynamics, it is possible that the random-dot-coherence and contrast manipulations targeted on different mechanisms for binocular rivalry (see next paragraph for further discussion). Further, Brascamp et al. (2006) showed that a decreasing contrast led to a longer transition duration in which both superimposition (fusion) or piecemeal percepts could occur (Hollins, 1980). They reported that percepts during transitional period between left- and right-eye images were mainly superimposition (fusion) percepts with low contrast (near threshold) rivalry stimuli; while the transitional percepts were predominantly piecemeal with high contrast rivalry stimuli. In our control experiment as well the main experiment, we used a high contrast (39-79\%), which were high enough for mainly seeing piecemeal percepts instead of fusion during the transitional period (Brascamp et al., 2006). In other words, the observed alcohol effects on piecemeal percepts could not be confounded with fusion percepts that we did not ask to report.

Binocular rivalry research has pointed to the importance of mutual inhibition, adaptation and neural noise in determining rivalry dynamics. Computational modeling indicates that mutual

\section{REFERENCES}

Alais, D. (2012). Binocular rivalry: competition and inhibition in visual perception. Wiley Interdiscipl. Rev. 3, 87-103. doi: 10.1002/wcs.151

Alais, D., and Blake, R. (1999). Grouping visual features during binocular rivalry. Vis. Res. 39, 4341-4353. doi: 10.1016/S0042-6989(99) 00146-7 inhibition and adaptation determines the percept choice based on two eye images, while neural noise is critical for transitional period (Brascamp et al., 2006; Huguet et al., 2014). Acute alcohol drinking is known to increase inhibition in the central nervous system. An increased inhibition between the representations of two images presented to two eyes is expected increase the mean dominance duration of coherent percepts. However, our study showed that the mean dominance duration for coherent percepts did not change significantly by alcohol intake. Therefore, our results could not be accounted for by alcohol's increase in inhibition. Previous studies have shown alcoholinduced slowdown in alternation rates when only coherent percepts were considered (Barany and Hallden, 1947; Donnelly and Miller, 1995). The current study showed that previous findings may result from the increased piecemeal percept duration rather than from a strengthened inhibition. Instead, the reduced number of coherent percepts might be resulting from the increased duration of piecemeal percepts during the transitional period. As seen in Figures 4 and 5, both the total predomaince time and the mean dominance duration were increased for piecemeal percepts after alcohol intake. Physiological investigations have shown that alcohol reduces signal-to-noise ratios or increases noise in the primary visual cortex (Chen et al., 2010). Given the importance of neural noise in transitional period of rivalry dynamics, it is likely acute alcohol drinking may affect the dynamics of piecemeal percepts by increasing neural noise (Brascamp et al., 2006). In sum, our study suggested that acute alcohol intake selectively increased the duration of piecemeal percepts, potentially by increasing neural noise, leading to a reduction in the number of coherent percepts.

\section{AUTHOR CONTRIBUTIONS}

DC and AK conceptualized the alcohol challenge paradigm. DC, $\mathrm{XZ}, \mathrm{PK}$, and $\mathrm{SH}$ designed the visual experiments. $\mathrm{PK}$ and $\mathrm{XZ}$ collected the data. DC and $\mathrm{SH}$ provided interpretation of the results. All contributed to manuscript writing and revision.

\section{ACKNOWLEDGMENTS}

This research was supported by ABMRF/Foundation for Alcohol Research (DC), Cless Family Foundation, P30EY01792 (UIC core grant for vision research), Unrestricted Departmental Grant from the Research to Prevent Blindness, and National Institute on Alcohol Abuse and Alcoholism R01AA013746 (AK).

Alais, D., Cass, J., O'Shea, R. P., and Blake, R. (2010). Visual sensitivity underlying changes in visual consciousness. Curr. Biol. 20, 1362-1367. doi: 10.1016/j.cub.2010.06.015

Barany, E. H., and Hallden, U. (1947). The influence of some central nervous depressants on the reciprocal inhibition between the two retinae as manifested in retinal rivalry. Acta Physiol. Scand. 13, 296-316. doi: 10.1111/j.17481716.1947.tb00466.x 
Blake, R. (1989). A neural theory of binocular rivalry. Psychol. Rev. 96, 145. doi: 10.1037/0033-295X.96.1.145

Blake, R., and Logothetis, N. K. (2002). Visual competition. Nat. Rev. Neurosci. 3, 13-21. doi: 10.1038/nrn701

Blake, R., O'Shea, R. P., and Mueller, T. J. (1992). Spatial zones of binocular rivalry in central and peripheral vision. Vis. Neurosci. 8, 469-478. doi: $10.1017 /$ S0952523800004971

Blake, R., Sobel, K. V., and Gilroy, L. A. (2003). Visual motion retards alternations between conflicting perceptual interpretations. Neuron 39, 869-878. doi: 10.1016/S0896-6273(03)00495-1

Brascamp, J. W., Klink, P. C., and Levelt, W. J. M. (2015). The 'laws' of binocular rivalry: 50 years of levelt's propositions. Vis. Res. 109, 20-37. doi: 10.1016/j.visres.2015.02.019

Brascamp, J. W., Van Ee, R., Noest, A. J., Jacobs, R. H., and van den Berg, A. V. (2006). The time course of binocular rivalry reveals a fundamental role of noise. J. Vis. 6, 1244-1256. doi: 10.1167/6.11.8

Brascamp, J. W., Van Ee, R., Pestman, W. R., and Van Den Berg, A. V. (2005). Distributions of alternation rates in various forms of bistable perception. J. Vis. 5, 287-298. doi: 10.1167/5.4.1

Brumback, T., Cao, D., and King, A. (2007). Effects of alcohol on psychomotor performance and perceived impairment in heavy binge social drinkers. Drug Alcohol Depend. 91, 10-17. doi: 10.1016/j.drugalcdep.2007. 04.013

Caetano, R., Clark, C. L., and Greenfield, T. K. (1998). Prevalence, trends, and incidence of alcohol withdrawal symptoms - analysis of general population and clinical samples. Alcohol Health Res. World 22, 73-80.

Cahalan, D., Cisin, I. H., and Crossley, H. M. (1969). American Drinking Practices: A National Study of Drinking Behavior and Patterns. New Brunswick, NJ: Rutgers Center of Alcohol Studies.

Casanova, J. A. A., Campos, J. A. A., Sánchez, M. M., and Supèr, H. (2013). Onset time of binocular rivalry and duration of inter-dominance periods as psychophysical markers of adhd. Perception 42, 16-27. doi: 10.1068 p7203

Chen, B., Xia, J., Li, G. X., and Zhou, Y. F. (2010). The effects of acute alcohol exposure on the response properties of neurons in visual cortex area 17 of cats. Toxicol. Appl. Pharmacol. 243, 348-358. doi: 10.1016/j.taap.2009.11.027

Chong, S. C., and Blake, R. (2006). Exogenous attention and endogenous attention influence initial dominance in binocular rivalry. Vis. Res. 46, 1794-1803. doi: 10.1016/j.visres.2005.10.031

Chong, S. C., Tadin, D., and Blake, R. (2005). Endogenous attention prolongs dominance durations in binocular rivalry. J. Vis. 5, 1004-1012. doi $10.1167 / 5.11 .6$

Donnelly, M., and Miller, R. (1995). Ingested ethanol and binocular rivalry. Invest. Ophthalmol. Vis. Sci. 36, 1548-1554.

Fries, P., Roelfsema, P. R., Engel, A. K., König, P., and Singer, W. (1997). Synchronization of oscillatory responses in visual cortex correlates with perception in interocular rivalry. Proc. Natl. Acad. Sci. U.S.A. 94, 12699-12704. doi: 10.1073/pnas.94.23.12699

Grobin, A. C., Matthews, D. B., Devaud, L. L., and Morrow, A. L. (1998). The role of gabaa receptors in the acute and chronic effects of ethanol. Psychopharmacology 139, 2-19. doi: 10.1007/s002130050685

Hancock, S., and Andrews, T. J. (2007). The role of voluntary and involuntary attention in selecting perceptual dominance during binocular rivalry. Perception 36, 288-298. doi: 10.1068/p5494

Hastorf, A., and Myro, G. (1959). The effect of meaning on binocular rivalry. Am. J. Psychol. 72, 393-400. doi: 10.3389/fpsyg.2011.00212

Hollins, M. (1980). The effect of contrast on the completeness of binocular rivalry suppression. Percept. Psychophys. 27, 550-556. doi: 10.3758/BF03198684

Huguet, G., Rinzel, J., and Hupé, J. (2014). Noise and adaptation in multistable perception: noise drives when to switch, adaptation determines percept choice. J. Vis. 14(3) 19, 11-24. doi: 10.1167/14.3.19

Kang, M. S., and Blake, R. (2010). What causes alternations in dominance during binocular rivalry? Attent. Percept. Psychophys. 72, 179-186. doi: 10.3758/APP.72.1.179

Khan, S. A., and Timney, B. (2007). Alcohol slows interhemispheric transmission, increases the flash-lag effect, and prolongs masking: evidence for a slowing of neural processing and transmission. Vis. Res. 47, 1821-1832. doi: 10.1016/j.visres.2007.03.008
King, A. C., de Wit, H., McNamara, P. J., and Cao, D. (2011). Rewarding, stimulant, and sedative alcohol responses and relationship to future binge drinking. Arch. Gen. Psychiatry 68, 389-399. doi: 10.1001/archgenpsychiatry. 2011.26

Kovács, I., Papathomas, T. V., Yang, M., and Fehér, Á (1996). When the brain changes its mind: interocular grouping during binocular rivalry. Proc. Natl. Acad. Sci. U.S.A 93, 15508-15511. doi: 10.1073/pnas.93.26. 15508

Kunchulia, M., Pilz, K. S., and Herzog, M. H. (2012). How alcohol intake affects visual temporal processing. Vis. Res. 66, 11-16. doi: 10.1016/j.visres.2012. 06.010

Lee, S. H., and Blake, R. (2004). A fresh look at interocular grouping during binocular rivalry. Vis. Res. 44, 983-991. doi: 10.1016/j.visres.2003.12.007

Lehky, S. R. (1988). An astable multivibrator model of binocular rivalry. Perception 17, 215-228. doi: 10.1068/p170215

Levelt, W. J. M. (1965). On Binocular Rivalry. Soesterberg: Institute for Perception RVO-TNO.

Mitchell, J. F., Stoner, G. R., and Reynolds, J. H. (2004). Object-based attention determines dominance in binocular rivalry. Nature 429, 410-413. doi: $10.1038 /$ nature 02584

Mueller, T. J., and Blake, R. (1989). A fresh look at the temporal dynamics of binocular rivalry. Biol. Cybern. 61, 223-232. doi: 10.1007/BF00198769

Paffen, C. L. E., Alais, D., and Verstraten, F. A. J. (2006). Attention speeds binocular rivalry. Psychol. Sci. 17, 752-756. doi: 10.1111/j.1467-9280.2006.01777.x

Pearson, P., and Timney, B. (1998). Effects of moderate blood alcohol concentrations on spatial and temporal contrast sensitivity. J. Stud. Alcohol. 59, 163-173. doi: 10.15288/jsa.1998.59.163

Platonov, A., and Goossens, J. (2013). Influence of contrast and coherence on the temporal dynamics of binocular motion rivalry. PLoS ONE 8:e71931. doi: 10.1371/journal.pone.0071931

Polonsky, A., Blake, R., Braun, J., and Heeger, D. J. (2000). Neuronal activity in human primary visual cortex correlates with perception during binocular rivalry. Nat. Neurosci. 3, 1153-1159. doi: 10.1038/80676

Sobell, L. C., Maisto, S. A., Sobell, M. B., and Cooper, A. M. (1979). Reliability of alcohol abusers' self-reports of drinking behavior. Behav. Res. Ther. 17, 157-160. doi: 10.1016/0005-7967(79)90025-1

Stollenwerk, L., and Bode, M. (2003). Lateral neural model of binocular rivalry. Neural Comput. 15, 2863-2882. doi: 10.1162/089976603322518777

Stuit, S. M., Paffen, C. L. E., van der Smagt, M. J., and Verstraten, F. A. J. (2011). What is grouping during binocular rivalry? Front. Hum. Neurosci. 5:117. doi: 10.3389/fnhum.2011.00117

Substance Abuse and Mental Health Services Administration [SAMHSA] (2005). National Survey on Drug use and Health Office of Applied Studies. Washington, DC: U.S. Department of Health and Human Services.

Theodoni, P., Panagiotaropoulos, T. I., Kapoor, V., Logothetis, N. K., and Deco, G. (2011). Cortical microcircuit dynamics mediating binocular rivalry: the role of adaptation in inhibition. Front. Hum. Neurosci. 5:145. doi: 10.3389/fnhum.2011.00145

Tong, F., Meng, M., and Blake, R. (2006). Neural bases of binocular rivalry. Trends Cogn. Sci. 10, 502-511. doi: 10.1016/j.tics.2006.09.003

Valenzuela, C. F. (1997). Alcohol and neurotransmitter interactions. Alcohol Health Res. World 21, 144-148.

van Loon, A. M., Knapen, T., Scholte, H. S., St John-Saaltink, E., Donner, T. H., and Lamme, V. A. F. (2013). Gaba shapes the dynamics of bistable perception. Curr. Biol. 23, 823-827. doi: 10.1016/j.cub.2013.03.067

Watson, P. E., Watson, I. D., and Batt, R. D. (1980). Total body water volumes for adult males and females estimated from simple anthropometric measurements. Am. J. Clin. Nutr. 33, 27-39.

Wilson, H. R. (2003). Computational evidence for a rivalry hierarchy in vision. Proc. Natl. Acad. Sci. U.S.A. 100, 14499-14503. doi: 10.1073/pnas.23336 22100

Wilson, H. R. (2007). Minimal physiological conditions for binocular rivalry and rivalry memory. Vis. Res. 47, 2741-2750. doi: 10.1016/J.Visres.2007. 07.007

Yu, K., and Blake, R. (1992). Do recognizable figures enjoy an advantage in binocular rivalry? J. Exp. Psychol. 18:1158.

Zeger, S. L., and Liang, K. Y. (1986). Longitudinal data-analysis for discrete and continuous outcomes. Biometrics 42, 121-130. doi: 10.2307/2531248 
Zhang, P., Jamison, K., Engel, S. A., He, B., and He, S. (2011). Binocular rivalry requires visual attention. Neuron 71, 362-369. doi: 10.1016/j.neuron.2011.05.035

Zhuang, X., Kang, P., King, A., and Cao, D. (2015). Alcohol intoxication impairs mesopic rod and cone temporal processing in social drinkers. Alcoholism 39, 1842-1849. doi: 10.1111/acer.12833

Zhuang, X., King, A. C., McNamara, P. J., Pokorny, J., and Cao, D. (2012). Differential effects of alcohol on contrast processing mediated by the magnocellular and parvocellular pathways. J. Vis. 6, 11-13. doi: $10.1167 / 12.11 .16$
Conflict of Interest Statement: The authors declare that the research was conducted in the absence of any commercial or financial relationships that could be construed as a potential conflict of interest.

Copyright $\odot 2016$ Cao, Zhuang, Kang, Hong and King. This is an open-access article distributed under the terms of the Creative Commons Attribution License (CC BY). The use, distribution or reproduction in other forums is permitted, provided the original author(s) or licensor are credited and that the original publication in this journal is cited, in accordance with accepted academic practice. No use, distribution or reproduction is permitted which does not comply with these terms. 